

\title{
BRICS e G7: a associação entre fatores contingenciais e estratégias competitivas influencia o desempenho financeiro empresarial?
}

\author{
BRICS and G7: does the association between contingency factors and competitive strategies \\ influence corporate financial performance?
}

BRICS y G7: la asociación entre factores de contingencia y estrategias competitivas influyen en el rendimiento financiero de las empresas?

\author{
Emanoel Truta do Bomfim* \\ Doutor em Ciências Contábeis (UFPB) \\ Professor do Departamento de Ciências Contábeis \\ (UNESC), Campina Grande/PB, Brasi \\ emanoeltruta@hotmail.com \\ https://orcid.org/0000-0003-1244-4437
}

\author{
Aldo Leonardo Cunha Callado \\ Doutor em Agronegócios (UFRGS) \\ Professor do Departamento de Finanças e Contabilidade (UFPB), João \\ Pessoa/PB, Brasil \\ aldocallado@yahoo.com.br \\ https://orcid.org/0000-0002-5393-6094
}

Endereço do contato principal para correspondência* Rua Rio Grande do Sul, 555, Bairro Quarenta, CEP: 58416-175 - Campina Grande/PB, Brasil

\section{Resumo}

O objetivo deste estudo foi analisar a relação da estratégia competitiva com os fatores contingenciais sobre o desempenho financeiro de empresas localizadas em países membros do BRICs e do G7. A amostra da pesquisa foi composta por 775 empresas (5.425 observações), sendo 172 localizadas na China, 33 na Índia, 48 na Alemanha, 25 no Canadá, 307 nos Estados Unidos da América, 169 no Japão e 21 no Reino Unido. Para estimar as relações entre as variáveis da pesquisa, aplicaram-se modelos de dados em painel dinâmico. As evidências encontradas sugerem que as estratégias competitivas (liderança em custos e diferenciação) podem moderar os efeitos dos fatores contingenciais sobre o desempenho financeiro das empresas, considerando o ambiente em que atuam (países membros do BRICs e do G7).

Palavras-chave: Estratégia competitiva; Fatores contingenciais; Desempenho financeiro

\begin{abstract}
The purpose of this study was to analyze the relationship between competitive strategy and contingency factors on the financial performance of companies located in member countries of the BRICS and the G7. The research sample comprised 775 companies (5,425 observations), 172 of which were located in China, 33 in India, 48 in Germany, 25 in Canada, 307 in the United States of America, 169 in Japan, and 21 in the United Kingdom. Dynamic panel data models were applied to estimate the relationships between the research variables. The evidence found suggests that competitive strategies (cost leadership and differentiation) can moderate the effects of contingency factors on the financial performance of companies, considering the environment in which they operate (BRICS or G7 member countries).
\end{abstract}

Keywords: Competitive strategy; Contingency factors; Financial performance

\section{Resumen}

El objetivo de este estudio fue analizar la relación entre la estrategia competitiva y los factores de contingencia en el desempeño financiero de las empresas ubicadas en los países miembros de los BRIC y el G7. La muestra de investigación comprendió 775 empresas (5,425 observaciones), 172 de las cuales se ubicaron en China, 33 en India, 48 en Alemania, 25 en Canadá, 307 en los Estados Unidos de América, 169 en Japón y 21 en el Reino Unido. Para estimar las relaciones entre las variables de investigación, se aplicaron modelos de datos de panel dinámico. Las evidencias encontradas sugieren que las estrategias competitivas (liderazgo en costos y diferenciación) pueden moderar los efectos de los factores de contingencia en el desempeño financiero de las empresas, considerando el entorno en el que operan (países miembros de los BRIC o G7).

Palabras clave: Estrategia competitiva; Factores de contingencia; Desempeño financiero 


\section{Introdução}

Segundo a teoria da contingência, para uma organização alcançar um desempenho superior, ela precisa se ajustar aos fatores presentes no ambiente, ou seja, aos fatores contingenciais internos e externos (Donaldson, 2015; Miller, 1992a). Isso exige que a entidade adapte estruturas e processos considerando o contexto externo (Miller, 1992b), sendo esta uma condição necessária para obter maior desempenho (Martins, 2019). Para tanto, faz-se necessário que a estrutura organizacional esteja alinhada com a estratégia (Donaldson, 1999), uma vez que a estratégia é quem determina a estrutura (Chandler Jr., 1962; Junqueira et al., 2016).

Segundo Anwar e Hasnu (2017), Chenhall (2003) e Gupta e Govindarajan (1984), a estratégia é considerada um fator contingencial diferente de outras variáveis contingenciais. Não é considerado um elemento de contexto externo, mas um meio pelo qual os gerentes podem influenciar a natureza do ambiente externo, as tecnologias da organização, os arranjos estruturais, entre outros fatores (Chenhall, 2003), sendo considerado um fator contingencial que pode ser utilizado para a organização se ajustar aos demais fatores contingenciais e obter desempenho diferenciado.

Para uma organização alcançar um desempenho financeiro superior, é necessário que obtenha e sustente uma vantagem competitiva no longo prazo (Banker et al., 2014; Huang et al., 2015). De acordo com Porter (2004), há apenas três estratégias competitivas capazes de gerar vantagem competitiva no longo prazo, permitindo que uma empresa crie uma posição defensável e capaz de enfrentar as forças de mercado, são elas: liderança em custos, diferenciação e enfoque. Estas três estratégias competitivas se fundamentam em duas fontes de vantagem competitiva: custo ou diferenciação.

Neste sentido, percebe-se que, para uma organização obter um desempenho superior, ela precisa ajustar sua estrutura aos fatores contingenciais presentes no ambiente, sendo a estratégia competitiva 0 meio pelo qual a entidade pode minimizar a influência desses fatores sobre o desempenho, gerando e mantendo um elevado desempenho financeiro no longo prazo.

Nos últimos anos, estudos vêm sendo desenvolvidos sobre o papel moderador da estratégia competitiva, avaliando sua influência sobre os impactos dos fatores contingenciais no desempenho organizacional (Acquaah \& Agyapong, 2016; Chen et al., 2018; Huo et al., 2014; Santos, 2015; Tenhiälä \& Laamanen, 2018). Contudo, a maioria desses estudos limita-se a analisar a mediação da estratégia competitiva sobre fatores contingenciais internos, como: integração da cadeia de suprimentos (Huo et al., 2014), clima organizacional (Shin, 2014), práticas de gestão operacional (Jayaram et al., 2014), capabilidades (Santos, 2015), sistema de controle gerencial (Acquaah \& Agyapong, 2016), nível de produção (Mohsenzadeh \& Ahmadian, 2016) e sistema de remuneração (Tenhiälä \& Laamanen, 2018), sendo que pesquisas sobre moderação da estratégia competitiva acerca dos fatores contingenciais externos ainda são escassas.

Os fatores contingenciais externos são elementos externos à organização que podem produzir ou gerar uma mudança organizacional (Ewsi-Mensah, 1981), atuando como uma força restritiva sobre as atividades corporativas, gerando pressão sobre a entidade e seus gestores, sendo moldados por clientes, competidores, fornecedores, governos e sindicatos (Ewsi-Mensah, 1981; Tung, 1979). Dentre as principais contingências externas, destacam-se: nível de competitividade ou hostilidade, tecnologia, incerteza de mercado e cultura nacional (Burkert et al., 2016; Chenhall, 2003; Junqueira et al., 2016; Mckinley \& Mone, 2003; Otley, 2016).

Chenhall (2003), Khandwalla (1972) e Otley (2016) consideram, por exemplo, que a incerteza do ambiente influencia a estrutura organizacional, a avaliação de desempenho, o sistema orçamentário e os sistemas gerenciais, entre outros, sendo que quanto maior for o nível de incerteza provocada pela intensa competição no ambiente, maior a necessidade de utilização de mais controles formais e técnicas contábeis sofisticadas.

Destarte, percebe-se que ambos os fatores contingenciais (internos e externos) exercem influência sobre a organização, provocando mudanças em suas atividades e estruturas corporativas, bem como no desempenho organizacional. Contudo, de acordo com Jayaram et al. (2014) e Parnell et al. (2015), a maioria das pesquisas sobre estratégia competitiva, fatores contingenciais e desempenho foi realizada em empresas de países desenvolvidos. Para Huo et al. (2014) e Parnell et al. (2015), é preciso que pesquisas abordem diferentes ambientes, não somente desenvolvidos, mas também países em desenvolvimento, uma vez que as características do ambiente (desenvolvido ou em desenvolvimento) são moldadas por diferentes fatores contingenciais externos e internos que provocam variações tanto na estrutura como no desempenho organizacional. Isto é, a influência dos fatores contingenciais pode variar de ambiente para ambiente.

Diante do exposto, e tendo o entendimento de que os fatores contingenciais tanto internos como externos afetam o desempenho organizacional, bem como que a estratégia competitiva pode ser considerada um meio pelo qual se pode reduzir a influência desses fatores sobre o desempenho financeiro, dependendo do ambiente, país em que a empresa atua, apresenta-se o seguinte problema de pesquisa: qual a relação da estratégia competitiva com os fatores contingenciais sobre o desempenho financeiro das empresas localizadas em países membros do BRICS e do G7? 
Para responder a este problema de pesquisa, buscou-se analisar a relação da estratégia competitiva com os fatores contingenciais sobre o desempenho financeiro de empresas localizadas em países membros do BRICS (Brasil, Rússia, Índia, China e África do Sul) e do G7 (grupo dos países mais industrializados do mundo). Do ponto de vista acadêmico, o trabalho contribui para a compreensão da relação entre os fatores contingenciais, a estratégia competitiva e o desempenho financeiro, dependendo do ambiente em que as empresas estão localizadas (países membros do BRICS ou do G7), conforme pressupostos da teoria da contingência. Na ótica da prática, demonstra a necessidade de as empresas se adequarem ao ambiente em que atuam (desenvolvido ou em desenvolvimento) por meio de uma estratégia competitiva que atue no sentido de reduzir as influências dos fatores contingenciais internos e externos sobre a estrutura e sistemas corporativos, uma vez que o desempenho organizacional pode depender do alinhamento com o ambiente.

\section{Revisão da Literatura}

\subsection{Fatores contingenciais}

De acordo com a teoria da contingência, para manter o nível de desempenho desejado, uma entidade precisa ajustar sua estrutura à(s) contingência(s) existente(s), identificando as variáveis contingenciais que afetam a sua estrutura e, por conseguinte, o desempenho corporativo (eficiência, eficácia, lucratividade e outros) (Chenhall, 2003; Donaldson, 1999; Hamann, 2017; Otley, 2016).

Os fatores contingenciais podem ser definidos como quaisquer variáveis relacionadas ao ambiente ou ao contexto empresarial (fatores externos), ou interno à entidade (fatores internos), que moldam a estrutura organizacional a qualquer momento, ou seja, influenciam na maneira como uma corporação desenvolve e estrutura suas atividades impactando o desempenho organizacional (Chenhall, 2003; Junqueira et al., 2016; Otley, 2016).

As variáveis ou fatores contingenciais podem ser elencados em fatores contingenciais externos e fatores contingenciais internos, conforme classificação sugerida por Otley (2016). Os principais fatores contingenciais externos englobam a tecnologia, o nível de competitividade ou hostilidade do mercado, a incerteza ambiental e a cultura nacional (Burkert et al., 2016; Chenhall, 2003; Junqueira et al., 2016; Mckinley \& Mone, 2003; Otley, 2016).

Evidências indicam que o tipo de tecnologia utilizado pode influenciar a estrutura organizacional, o sistema de controle gerencial, o sistema de informação corporativo e contábil, entre outros (Chenhall, 2003; Xiao et al., 1996); que a incerteza afeta a estrutura e os sistemas organizacionais (comunicação, informação, controle, gerencial etc.), moldando as características das entidades (Chenhall, 2003; Otley, 2016; Tung, 1979); e que a cultura nacional afeta as práticas gerenciais, o processo orçamentário entre empresas localizadas em diversos países, a participação no orçamento e na avaliação de desempenho praticado na matriz e em suas subsidiárias, o sistema de controle gerencial e o sistema de remuneração (Chenhall, 2003; Filatotchev \& Allcock, 2010; Harrison, 1993; Hofstede, 1983; Otley, 2016; Snodgrass \& Grant, 1986).

Pesquisas realizadas (Boyd \& Salamin, 2001; Chenhall, 2003; Combs \& Skill, 2003; Filatotchev \& Allcock, 2010) indicam que o tipo de estrutura pode influenciar a eficiência do trabalho, a motivação dos indivíduos, o fluxo de informações e o sistema de controle, e podem moldar o futuro da entidade; que o sistema de compensação exerce um papel importante no recrutamento, motivação e retenção de empregados e executivos, podendo ser utilizado como um meio estratégico para a obtenção de gerentes habilidosos e de capital humano necessário para o desenvolvimento organizacional; e, que a estratégia afeta a estrutura organizacional (Chandler Jr., 1962), demonstrando a influência desses fatores contingenciais internos sobre a estrutura e o desempenho corporativo.

\subsection{Estratégias competitivas}

A estratégia competitiva, também denominada de estratégia genérica competitiva ou estratégia principal, entre outras denominações, envolve o estabelecimento de um posicionamento estratégico geral que pode ser adotado por qualquer organização, independentemente do ramo de negócio (Chaves et al., 2009; Herbert \& Deresky, 1987).

Uma estratégia competitiva pode ser definida por inúmeros caminhos ou visões, apresentando pontos comuns que a caracterizam como um conjunto de diretrizes que buscam determinar uma decisão no futuro, ou o meio que uma organização escolheu para atingir seus objetivos, metas e resultados (Capalonga et al., 2014; Chaves et al., 2009; Mintzberg, 1978; Rugman \& Verbeke, 1994). A literatura apresenta algumas tipologias de estratégias competitivas, dentre as quais se destacam as de Gupta e Govidarajan (1984), Miles et al. (1978) e Porter (1980).

As estratégias genéricas de Miles et al. (1978) são baseadas no ciclo de adaptação da organização. Segundo os autores, pela perspectiva das escolhas estratégicas, o comportamento de uma organização é parcialmente pré-ordenado pelas condições ambientais, e as decisões que os altos executivos tomam são 
determinantes críticos da estrutura e do processo organizacional.

Para Miles et al. (1978), a gestão de uma entidade deve enfrentar três tipos de problemas relacionados à estrutura e ao processo organizacional: o empreendedor (a gestão estratégica de produtos e mercados), a tecnologia (a produção e a distribuição de produtos) e a administração (da organização, para apoiar o empreendedor e as decisões tecnológicas). Ainda segundo os autores, com a solução destes problemas, a entidade poderá escolher uma abordagem estratégica mais adequada à sua estrutura e aos seus processos organizacionais.

Com base na análise de como os problemas do empreendedor são solucionados, bem como do comportamento organizacional, Miles et al. (1978) identificaram quatro tipos de estratégicas corporativas, a saber: prospectora, defensiva, analítica e reativa. A abordagem prospectora é utilizada por uma firma quando ela busca intensamente novas e pioneiras oportunidades de produtos e mercados, mesmo que tenha que sacrificar seu nível de rentabilidade (Andrade et al., 2013).

$\mathrm{Na}$ estratégia defensiva, a companhia está sempre buscando a estabilidade do negócio, por meio da liderança de seus produtos em um determinado segmento de mercado. Além disso, por meio desta escolha estratégica, a empresa procura praticar preços competitivos ou investe na qualidade de seus produtos e serviços para garantir sua participação no mercado (Miles et al., 1978).

Com relação à estratégia analítica, segundo Miles et al. (1978), as organizações que adotam este modelo estratégico procuram combinar as bases e peculiaridades das abordagens prospectora e defensiva para otimizar e maximizar suas oportunidades de lucratividade, ou seja, trata-se de uma estratégia intermediária. Já pela estratégia reativa, na visão de Miles et al. (1978), a entidade busca apenas reagir ao ambiente, principalmente quando se vê ameaçada pela concorrência. Para os autores, neste modelo, a firma atua como se não tivesse estratégia, procurando apenas acompanhar as mudanças ocorridas no mercado.

Em outra vertente, surgem as abordagens estratégicas de Gupta e Govindarajan (1984). Para a formulação de suas estratégias, os autores tomaram como base o ciclo de vida organizacional e a missão estratégica. Segundo eles, uma entidade vai escolher sua missão estratégica com base na fase de ciclo de vida em que o mercado e o produto se coincidem.

Para Gupta e Govindarajan (1984), a partir da análise do equilíbrio das metas de crescimento da participação da empresa no mercado e da maximização da rentabilidade no curto prazo, a organização poderá optar por quatro modelos estratégicos: construção, colheita, manutenção e renúncia.

$\mathrm{Na}$ estratégia de construção, a entidade almeja aumentar sua participação no mercado e o seu nível de competitividade, mesmo que tenha menores ganhos e fluxos de caixa baixos no curto prazo. Já na abordagem de colheita, o objetivo da organização é aumentar seus lucros e seus fluxos de caixa, ainda que tenha que reduzir sua participação no mercado. Com relação à estratégia de manutenção, observa-se que a entidade busca coadunar os objetivos das estratégias de construção e colheita. E, na abordagem de renúncia, a companhia escolhe finalizar suas operações (Gupta \& Govindarajan, 1984).

Verifica-se que, por meio das estratégias propostas por Gupta e Govidarajan (1984), a empresa só conseguirá maximizar seus resultados quando sua estratégia estiver alinhada com a fase de ciclo de vida de seus produtos e com a do mercado, podendo tal objetivo ser alcançado por meio da missão estratégica traçada pela entidade.

Por sua vez, o modelo de abordagem estratégico mais utilizado nos estudos empíricos é o proposto por Porter (1986). Porter (2004) descreve duas estratégias genéricas para que uma empresa possa obter vantagens competitivas sobre seus concorrentes: a liderança em custos e diferenciação em produtos. Organizações que adotam uma estratégia baseada na liderança em custos buscam aumentar seu poder de mercado com base na criação de uma posição de baixo custo em relação aos seus concorrentes. Uma empresa pode desenvolver diversos processos e práticas de alocação de recursos para obter a liderança em custos, tais como: instalações em grande escala, melhorias de processos, minimização de custos, gestão da qualidade total, benchmarking e alto controle de custos (Allen \& Helms, 2006; Banker et al., 2014; Porter, 2004).

Segundo Andrade et al. (2013), a liderança em custo total exige que uma companhia invista constantemente em seu capital, otimize sua engenharia de processos e desenvolva sistemas de produção de baixos custos, buscando fabricar seus produtos com custos inferiores aos de seus concorrentes. A estratégia de liderança em custos é efetivamente aplicada por uma empresa quando a sua estrutura, sua produção e o mercado de seus produtos são mais eficientes do que o de seus concorrentes (Allen \& Helms, 2006).

Uma estratégia baseada na diferenciação, por sua vez, é aquela em que uma empresa foca seus esforços em disponibilizar um produto ou serviço exclusivo para seus clientes. Nesta estratégia, a organização concorre com produtos e serviços exclusivos e diferenciados da concorrência, em qualidade e funcionalidade, mediante capacidades específicas e talentos criativos (Allen \& Helms, 2006; Andrade et al., 2013).

Desta forma, pode-se dizer que a abordagem estratégica utilizada por uma entidade desempenha um papel importante em suas operações, além de ser uma variável contingencial interna que se relaciona com os demais fatores contingenciais, como, por exemplo, estrutura e ambiente, que podem influenciar o 
desempenho econômico-financeiro corporativo.

\subsection{Estudos anteriores}

Poucos são os estudos que atribuem à estratégia competitiva o papel de variável contingencial moderadora entre os demais fatores contingenciais e o desempenho organizacional. Mediante uma revisão sistemática da literatura, foram identificadas as seguintes pesquisas: Acquaah e Agyapong (2016), Chen et al. (2018), Hernández-Perlines et al. (2016), Huo et al. (2014), Jayaram et al. (2014), Mohsenzadeh e Ahmadian (2016), Santos (2015), Shin (2014), Tenhiälä e Laamanen (2018).

A partir da análise desses estudos, no que se refere aos que utilizaram a estratégia competitiva como um fator que modera a influência dos fatores contingenciais sobre o desempenho organizacional, observou-se tal relação com práticas de integração de cadeias de suprimentos (Huo et al., 2014), práticas operacionais e gestão da cadeia de suprimentos (Jayaram et al., 2014), adoção de sistemas de trabalho de alto desempenho (Shin, 2014), sistema de controle gerencial (Acquaah \& Agyapong, 2016), orientação empreendedora (Hernández-Perlines et al., 2016), capabilidades e capacidades organizacionais (Mohsenzadeh \& Ahmadian, 2016; Santos, 2015) e responsabilidade social corporativa (Chen et al., 2018).

Dentre os estudos examinados, apenas o de Parnell et al. (2015) buscou avaliar a relação entre fatores contingenciais (incerteza do ambiente), estratégia competitiva e desempenho organizacional, avaliando empresas dos Estados Unidos da América (EUA) e da China, comparando organizações que atuam em um ambiente desenvolvido com as que operam em um mercado em desenvolvimento. Segundo os autores, devido às mudanças ocorridas na China, as companhias evitam a incerteza e buscam informações mais claras antes de implementarem estratégias, algo que não ocorre nos EUA, onde o ambiente é mais estável e as mudanças ocorrem de forma mais gradual.

Pode-se dizer que a maioria dos estudos analisados não buscou verificar se o papel moderador da estratégia competitiva varia de acordo com o ambiente em que as empresas operam (países desenvolvidos ou em desenvolvimento), conforme predito pela teoria da contingência. Além disso, a maior parte das evidências encontradas se refere à influência da estratégia competitiva sobre fatores contingenciais relacionados ao ambiente interno das organizações, tais como: estrutura organizacional, sistema de controle gerencial, práticas operacionais, entre outros.

\section{PROCEDIMENTOS METODOLÓGICOS}

\subsection{População, amostra e dados da pesquisa}

A população desta pesquisa foi composta por empresas de capital aberto listadas em bolsas de valores de países membros do BRICS e do G7. De acordo com o Fundo Monetário Internacional International Monetary Fund (IMF, 2019), o G7 é formado pelas economias mais avançadas e desenvolvidas do mundo, sendo composto por Alemanha, Canadá, EUA, França, Itália, Japão e Reino Unido.

Já o BRICS é um grupo de países composto por Brasil, Rússia, Índia, China e África do Sul. Os países do BRICS se destacaram por apresentarem elevado potencial e rápido crescimento econômico, tornando-se líderes no desenvolvimento de novos bens e serviços (Fedato et al., 2017). Desta forma, a escolha das empresas pertencentes aos países membros do G7 e do BRICS possibilita analisar a relação da estratégia competitiva com os fatores contingenciais (internos e externos) sobre o desempenho financeiro das organizações, considerando-se a característica do ambiente em que atuam, uma vez que os ambientes abordados apresentam diferentes estágios de desenvolvimento econômico, institucional, social e cultural, influenciando a estratégia adotada pelas companhias.

A amostra foi constituída pelas companhias não financeiras que possuíssem dados para análise considerando-se o período de 2012 a 2018. Também foram excluídas da amostra empresas de utilidade pública, visto que essas organizações atuam em ambientes regulados, podendo haver baixo nível de competição entre as entidades e regulamentação de preços, influenciando o desempenho e a estratégia competitiva, sendo que, em muitos casos, o posicionamento estratégico não é tão bem definido (Banker et al., 2014). A amostra final da pesquisa foi composta por 775 empresas (5.425 observações), sendo 172 da China, 33 da Índia, 48 da Alemanha, 25 do Canadá, 307 dos EUA, 169 do Japão e 21 do Reino Unido. As empresas do Brasil, da África do Sul, da Rússia, da França e da Itália foram excluídas da amostra, visto que não apresentaram informações sobre gastos com pesquisa e desenvolvimento (P\&D) e número de empregados suficientes para estimar a estratégia competitiva. Os dados para a realização deste estudo foram coletados no banco de dados da Thomson Reuters ${ }^{\circledR}$ e, quando necessário, nas demonstrações contábeis e/ou em outros relatórios disponibilizados pelas empresas, como o relatório da administração ou de sustentabilidade, além dos sítios das companhias na Internet. Já as informações sobre o crescimento econômico de cada país foram obtidas no sítio do IMF (2019).

Para a obtenção das variáveis financeiras da pesquisa, consideraram-se as demonstrações consolidadas das companhias, quando disponíveis na base de dados da Thomson Reuters ${ }^{\circledR}$, ou os dados 
não consolidados, quando aqueles não estavam disponíveis. Além disso, todos os dados contábeisfinanceiros foram padronizados para o dólar norte-americano, uma vez que tais informações eram divulgadas nas moedas de cada país. Esse procedimento permitiu a comparabilidade dos dados contábeis, bem como reduziu os efeitos da variação na taxa de câmbio no desempenho financeiro das organizações (Paredes \& Wheatley, 2017).

\subsection{Descrições dos modelos econométricos e variáveis da pesquisa}

Para analisar a estratégia competitiva (liderança em custos e diferenciação) que pode reduzir a influência dos fatores contingenciais (incerteza do ambiente, nível de competitividade, cultura nacional, ciclo de vida e tamanho organizacional) sobre o desempenho financeiro de empresas, considerando-se 0 ambiente em que estão localizadas (países desenvolvidos e em desenvolvimento), adaptou-se o modelo proposto por Banker et al. (2014).

Com base nos objetivos da pesquisa, a relação entre as variáveis da pesquisa foi estimada a partir do modelo empírico de Banker et al. (2014), acrescentado das variáveis referentes aos fatores contingenciais, crescimento econômico, setor industrial e país, conforme Equação 1:

$$
\begin{gathered}
D F_{i t+1}=\alpha_{0}+\alpha_{1} D F_{i t}+\alpha_{2} L C_{i t}+\alpha_{3} D I F_{i t}+\alpha_{4} N C_{j t}+\alpha_{5} I N C_{i t}+\alpha_{6} I D_{i t}+\alpha_{7} P E Q_{i t}+\alpha_{8} G P_{i t}+\alpha_{9} E N D_{i t}+ \\
\alpha_{10} C E_{j t}+\alpha_{11} D I n d+\alpha_{12} D P a i ́ s+\varepsilon_{i t}
\end{gathered}
$$

Em que,

- $D F_{\text {it }}$ é o desempenho financeiro da companhia $i$ no período $t$, calculado com base nos retornos dos ativos (ROA);

- $D F_{i t-1}$ é o desempenho financeiro da companhia $i$ no período $t-1$, calculado com base nos retornos dos ativos (ROA);

- $L C_{i t}$ o escore fatorial para a estratégia liderança em custos para a empresa $i$ no período $t$; mensurada com base no constructo obtido a partir da média de $t-1$ a $t-5$ das variáveis RL/CAPEX, RL/AIL e NE/AT;

- $D I F_{i t}$ é o escore fatorial para a estratégia de diferenciação da empresa $i$ no período $t$; mensurada com base no constructo obtido, a partir da média de $t-1$ a $t-5$ das variáveis $D V G A / R L, P \& D / R L$ e $\mathrm{VA} / \mathrm{RL}$;

- $N C_{\text {it }}$ é o nível de competitividade no setor $j$ no período $t$, calculado com base no índice de Herfindahl;

- INC $C_{j t}$ é o grau de incerteza da companhia $i$ no período $t$, mensurado com base no coeficiente de variação das receitas;

- $I D_{i t}$ é a idade da organização $i$ no período $t$, mensurada com base na idade de cada empresa;

- $P E Q_{i t}$ é uma variável dummy que representa valor igual a 1 , se a empresa $i$ no período $t$ for considerada de pequeno porte, ou 0 , caso contrário, mensurada a partir da classificação em quartis do logaritmo natural do número de empregados;

- $G P_{i t}$ é uma variável dummy que representa valor igual a 1 , se a empresa $i$ no período $t$ for considerada de grande porte, ou 0 , caso contrário, mensurada a partir da classificação em quartis do logaritmo natural do número de empregados;

- $E N D_{\text {it }}$ é o grau de endividamento da empresa $i$ no período $t$, mensurado pela relação entre o passivo oneroso e o ativo total;

- $C E_{j t}$ é o crescimento econômico do ambiente (país) j no período $t$, mensurado pela variação no produto interno bruto (PIB);

- DInd é uma variável dummy que assume valor igual a 1 ou 0 , de acordo com a indústria organizacional;

- DPaís é uma variável dummy, que assume valor igual a 1, se o ambiente (país) for considerado desenvolvido, ou 0 , caso contrário; e

- $\varepsilon_{i t}$ são os erros da regressão.

A partir das estimações da Equação 1, pode-se avaliar as relações entre as variáveis explicativas e o desempenho financeiro das companhias, possibilitando identificar a estratégia competitiva e os fatores contingenciais que afetaram a performance das firmas no período investigado. Já para avaliar a estratégia competitiva $(E C)$ que pode reduzir as influências dos fatores contingenciais externos ( $F C E)$ e internos $(F C l)$ sobre o desempenho financeiro das empresas, conforme tese proposta por este estudo, foram adicionadas na Equação 2 variáveis de interação entre os fatores contingenciais externos $\left(N C_{j t}\right.$ e $\left.I N C_{i t}\right)$ e os fatores contingenciais internos $\left(I D_{i t}, P E Q_{i t}\right.$ e $\left.G P_{i t}\right)$ com as estratégias competitivas (liderança no custo e diferenciação), conforme descrito na Equação 2:

$$
D F_{i t}=\beta_{0}+\alpha_{1} D F_{i t-1}+\sum_{k=1}^{3} \gamma_{k} F C E_{i t} \times E C_{i t}+\sum_{m=1}^{2} \delta_{m} F C I_{i t} \times E C_{i t} \sum_{n=1}^{4} \varphi_{n} V C_{i t}+\varepsilon_{i t}
$$


Em que:

- $D F_{i t+1}$ é o desempenho financeiro da companhia $i$ no período $t+1$, calculado com base nos retornos dos ativos (ROA);

- $D F_{i t}$ é o desempenho financeiro da companhia i no período $t$, calculado com base nos retornos dos ativos (ROA);

- $F C E_{i t}$ são os fatores contingenciais externos do ambiente da organização $i$ no período $t$, mensurados pelas variáveis $N C_{j t}$ e $I N C_{i t}$;

- $F C l_{i t}$ são os fatores contingenciais internos do ambiente da organização $i$ no período $t$, mensurados pelas variáveis $I D_{i t}, P E Q_{i t}$ e $G P_{i t}$;

- $E C_{i t}$ indica a estratégia competitiva da empresa $i$ no período $t$ baseada na liderança em custos $\left(L C_{i t}\right)$, ou na diferenciação $\left(D F I_{i t}\right)$;

- $V C_{i t}$ são as variáveis de controle do modelo (grau de endividamento, setor industrial, crescimento econômico e país em que a organização atua); e

- $\varepsilon_{i t}$ são os erros da regressão.

A relação da estratégia competitiva com os fatores contingenciais foi obtida com base no sinal dos coeficientes angulares de cada interação entre essas variáveis. As variáveis da pesquisa foram calculadas conforme a Tabela 1.

Tabela 1:

Definição das variáveis explicativas

\begin{tabular}{|c|c|c|c|}
\hline Variável & Descrição & Cálculo & $\begin{array}{c}\text { Sinal } \\
\text { esperado }\end{array}$ \\
\hline$R O A_{i t-1}$ & Retorno dos ativos & Lucro operacional dividido pelo ativo médio total. & + \\
\hline$L C_{i t}$ & $\begin{array}{l}\text { Estratégia de liderança em } \\
\text { custos }\end{array}$ & $\begin{array}{l}\text { Mensurada com base no constructo obtido a partir da média de } t-1 \text { a } t-5 \text { das } \\
\text { variáveis RL/CAPEX, RL/AIL e NE/AT; }\end{array}$ & + \\
\hline$D I F_{i t}$ & $\begin{array}{l}\text { Estratégia de } \\
\text { diferenciação }\end{array}$ & $\begin{array}{l}\text { Mensurada com base no constructo obtido, a partir da média de } t-1 \text { a } t-5 \text { das } \\
\text { variáveis } D V G A / R L, P \& D / R L \text { e VA/RL. }\end{array}$ & + \\
\hline$N C_{j t}$ & Nível de competição & Calculado com base no índice Herfindahl. & - \\
\hline$I N C_{i t}$ & Nível de incerteza & Mensurado com base no coeficiente de variação das receitas. & - \\
\hline$I D_{i t}$ & Idade da organização & Calculada com base na idade de cada empresa. & + \\
\hline$P E Q_{i t}$ & $\begin{array}{l}\text { Empresa de pequeno } \\
\text { porte }\end{array}$ & $\begin{array}{l}\text { Variável dummy que representa valor igual a } 1 \text {, se a empresa } i \text { no período } t \text { for } \\
\text { considerada de pequeno porte, ou } 0 \text {, caso contrário. }\end{array}$ & + \\
\hline$G P_{\text {it }}$ & Empresa de grande porte & $\begin{array}{l}\text { Variável dummy que representa valor igual a } 1 \text {, se a empresa } i \text { no período } t \text { for } \\
\text { considerada de grande porte, ou } 0 \text {, caso contrário. }\end{array}$ & + \\
\hline$E N D_{i t}$ & Endividamento & Mensurado pela relação entre o passivo oneroso e o ativo total; & - \\
\hline$C E_{j t}$ & Crescimento econômico & Calculado pela variação no PIB. & \\
\hline DInd & Dummy setor industrial & $\begin{array}{l}\text { Variável dummy que assume valor igual a } 1 \text { ou } 0 \text {, de acordo com a indústria } \\
\text { organizacional. }\end{array}$ & \\
\hline DPaís & Dummy país & $\begin{array}{l}\text { Variável dummy, que assume valor igual a } 1 \text {, se o ambiente (país) for } \\
\text { considerado desenvolvido, ou } 0 \text {, caso contrário. }\end{array}$ & \\
\hline
\end{tabular}

Fonte: elaboração própria.

As variáveis explicativas utilizadas nesta pesquisa foram escolhidas com base na literatura e em estudos anteriores sobre o tema (Balsam et al., 2011; Banker et al., 2014; Chenhall, 2003; Hambrick, 1983; Otley, 2016). A escolha da incerteza do ambiente e do nível de competitividade, como fatores contingenciais externos, por exemplo, justifica-se por representarem aspectos do ambiente externo que podem influenciar a estrutura organizacional e o desempenho das empresas (Chenhall, 2003; Otley, 2016). Além disso, ambientes caracterizados por altos níveis de incerteza e competição provocam mudanças nos sistemas gerenciais e na utilização de técnicas contábeis avançadas (Khandwalla, 1972; Otley, 2016). Outros fatores contingenciais externos, como cultura nacional e tecnologia, não foram utilizados, porque os bancos de dados utilizados não disponibilizavam informações a respeito deles, dificultando o emprego dessas variáveis.

Já as variáveis que representam os fatores contingenciais internos (idade da organização e porte/tamanho) refletem o desenvolvimento das empresas ao longo dos anos e seu crescimento, podendo indicar as mudanças que fizeram para continuar eficientes e terem maior controle do ambiente em que operam (Greiner, 1972), sendo que o aumento do porte pode afetar tanto a estrutura organizacional como os níveis de controles (Chenhall, 2003; Otley, 2016).

\subsection{Métodos de análise}

Inicialmente, para identificar as estratégias competitivas, empregou-se uma análise fatorial exploratória a fim de encontrar os padrões comuns entre as variáveis. Posteriormente, foi conduzida uma análise fatorial confirmatória para validar os dois constructos que representam a estratégia de diferenciação e de liderança em custos. Os resultados da análise fatorial exploratória e confirmatória encontram-se nas Tabelas 2 e 3, na seção seguinte.

A análise fatorial exploratória foi utilizada com o objetivo de capturar os padrões comuns entre os 
itens que compõem os constructos das estratégias competitivas (liderança em custos e diferenciação). Com base na análise fatorial exploratória, observou-se a adequação dos itens para cada constructo (Hair Jr. et al., 2009). Para tanto, foram verificados os seguintes critérios: (a) tipos de variáveis: a maioria foi contínua; (b) tamanho da amostra: deveria ser de, no mínimo, 5 observações para cada variável, foram utilizadas 6 variáveis (3 para o constructo de liderança em custos e 3 para diferenciação), sendo, portanto, necessárias, no mínimo, 30 observações, mas a amostra deste estudo considerou mais de 5.000 observações; e (c) padrão de correlação: o padrão de correlação entre as variáveis deve apresentar cargas fatoriais maiores que 0,30 na análise fatorial confirmatória (Hair Jr. et al., 2009).

A adequação da amostra foi obtida por meio do teste de Kaiser-Meyer-Olklin (KMO). A estatística KMO varia entre 0 e 1, sendo que quanto mais próximo de 1, melhor é adequação dos dados. $\mathrm{O}$ valor aceitável para o teste de KMO é de 0,50. Já a significância foi verificada a partir do teste de esfericidade de Bartlett. Esse teste mensura a significância estatística de que a matriz de correlações apresenta correlações significantes entre as variáveis. O valor da significância do teste ( $p$-valor) deve ser inferior a 0,05 $(p<0,05)$ (Hair Jr. et al., 2009).

Para extrair os fatores, empregou-se o método dos componentes principais. Esse método considerou a variância total dos dados. Já o critério utilizado para avaliação dos fatores foi a análise de comunalidades. A comunalidade indica o total de variância que uma variável compartilha com as demais variáveis incluídas na análise. Deve-se avaliar a comunalidade para verificar se as variáveis atendem aos níveis aceitáveis de explicação, sendo admitidos variáveis com valores maiores ou iguais a 0,50 (Hair Jr. et al., 2009).

Por sua vez, a análise fatorial confirmatória foi empregada para testar se as variáveis utilizadas para identificar as estratégias competitivas (liderança em custos e diferenciação) representam adequadamente esses constructos. O objetivo da análise fatorial confirmatória é medir o grau de ajustamento entre os dados observados com o previsto na teoria. Para avaliar a validade dos constructos, deve-se analisar a validade convergente (variância comum compartilhada entre as variáveis do construto) e a validade discriminante (indica em que grau um construto é diferente das demais) (Hair Jr. et al., 2009).

A validade convergente pode ser obtida: (a) por meio das cargas padronizadas, as quais devem apresentar valores entre 0,50 ou mais, sendo valores iguais ou maiores que 0,70 o ideal; (b) pelo percentual médio da variância extraída (average variance extracted), cujos valores aceitáveis devem ser superiores a 0,50; e (c) pelo alfa de Cronbach, em que um valor entre 0,6 e 0,7 é considerado aceitável e um valor acima de 0,7 ou mais sugere um bom nível de confiabilidade (Field, 2009; Hair Jr. et al., 2009). Para avaliar a validade convergente, observou-se o percentual médio da variância extraída.

Dois testes podem ser utilizados para mensurar a validade discriminante da análise fatorial confirmatória: a análise das cargas cruzadas e o critério Fornell-Larcker (1981). Na análise das cargas cruzadas, observa-se se a carga do indicador relativa ao construto latente associado está mais alta do que a carga por ele apresentada nos demais constructos do modelo. Por sua vez, no critério de Fornell-Larcker (1981), verifica-se se um construto latente compartilha mais variância com seus indicadores do que com qualquer outra medida latente do modelo. Nesse critério, o valor da variância média extraída de cada constructo latente deve ser maior que a correlação quadrática mais alta de qualquer outro constructo latente (Hair et al., 2011). O critério de Fornell-Larcker (1981) foi utilizado para analisar a validade discriminante dos constructos.

Portanto, a partir da análise fatorial confirmatória, verifica-se se as variáveis utilizadas representam as estratégias de diferenciação e liderança em custos, conforme previsto pela literatura, ou seja, que empresas que competem com baixo custo buscam maior eficiência de suas atividades, enquanto firmas que buscam diferenciar seus produtos no mercado realizam altos investimentos em P\&D, por exemplo. Os resultados da análise fatorial exploratória e confirmatória encontram-se nas Tabelas 2 e 3 , na seção seguinte.

Já as relações entre os fatores contingenciais, as estratégias competitivas e o desempenho financeiro das companhias foram estimados com base no modelo de dados em painel na forma dinâmica. $O$ modelo de dados em painel na forma dinâmica é aplicável quando há a inclusão da variável dependente defasada entre as variáveis explicativas (Baltagi, 2005). A estimação do modelo econométrico a partir de outras técnicas estatísticas, como o método dos mínimos quadrados ordinários, poderia gerar coeficientes enviesados e inconsistentes, uma vez que a variável dependente defasada é correlacionada com os erros da regressão e devido à existência de endogeneidade das variáveis explicativas (Baltagi, 2005).

Para resolver tais problemas, Arrelano e Bond (1991) propuseram o método dos momentos generalizados em primeira diferença - generalized method of moments (GMM). O método consiste em eliminar os efeitos fixos por meio da primeira diferença entre as equações do modelo e na utilização de valores da variável defasada em um ou mais períodos como variáveis instrumentais válidas na equação, ou, em último caso, em dois ou mais períodos, caso as primeiras variáveis instrumentais não sejam válidas (Arrelano \& Bond, 1991).

A consistência e a robustez do modelo dependem da premissa de ausência de correlação serial nos erros da regressão e da validade dos instrumentos adicionais (Baltagi, 2005; Labra \& Torrecillas, 2018). Para que os estimadores da regressão sejam consistentes, deve-se rejeitar a hipótese de ausência de 
autocorrelação de primeira ordem, mas aceitar o de segunda ordem. Em seguida, aplicou-se o teste de Hansen para sobreidentificação e para aferir se os instrumentos utilizados são válidos.

\section{Resultados da Pesquisa}

\subsection{Análise fatorial exploratória e confirmatória das estratégias competitivas}

Para capturar a estratégia competitiva de longo prazo de cada empresa, foi computada a média das variáveis DVGA/RL, P\&D/RL, VA/RL, CAPEX/RL, AlL/RL e AT/NE considerando o período de 2011 a 2017. Depois, foi realizada uma análise fatorial exploratória para capturar o padrão comum para as seis variáveis descritas. Os resultados estão apresentados na Tabela 4, para empresas da China e da Índia, e na Tabela 5, para companhias localizadas em países do G7.

Inicialmente, analisando-se as comunalidades das variáveis, conforme consta no Painel A das Tabelas 2 e 3, apenas as variáveis P\&D/RL $(0,34)$ e AT/NE $(0,188$ e 0,39), respectivamente, apresentaram comunalidades inferiores a 0,50, sendo necessário excluir tais variáveis, conforme Hair et al. (2009). Contudo, decidiu-se deixar essas variáveis, uma vez que, apesar de apresentarem uma comunalidade baixa, tais itens contribuem com uma carga fatorial superior a 0,30 para os fatores, bem como por serem apontadas por outros estudos como indicadores da estratégia de diferenciação e de liderança em custos, respectivamente (Asdemir et al., 2017; Balsam et al., 2011; Banker et al., 2014; Hambrick, 1983). Além disso, os resultados da análise fatorial confirmatória (Painel B das Tabelas 2 e 3 ) indicaram que tais variáveis também representam os constructos.

Tabela 2:

Análise fatorial exploratória e confirmatória dos constructos: empresas de países membros do BRICS



Com base nas cargas fatoriais expostas no Painel A das Tabelas 2 e 3 , as variáveis foram agrupadas em duas estratégias competitivas, a saber: liderança em custos e diferenciação. As variáveis DVGA/RL, $P \& D / R L$ e VA/RL foram agrupadas no fator diferenciação, pois apresentaram as maiores cargas fatoriais nesse constructo. Por exemplo, a variável DVGA/RL, conforme Painel $A$, contribui com maior carga fatorial para o fator diferenciação (carga fatorial $=0,83$ ), mas contribui negativamente para o constructo liderança em custos (carga fatorial $=-0,43$ ).

Já as variáveis CAPEX/RL, AIL/AIL e AT/NE, com base nas cargas fatoriais, foram agregadas na estratégia baseada na liderança em custos, conforme Painel A das Tabelas 2 e 3. Tais resultados estão de acordo com o previsto na literatura (Balsam et al., 2011; Banker et al., 2014; Hambrick, 1983), indicando 
que essas variáveis podem explicar a estratégia competitiva adotada pelas companhias para os dois grupos analisados.

A consistência interna dos fatores foi avaliada por meio do alfa de Cronbach. Os resultados do teste demonstraram que a consistência interna para os dois fatores, liderança em custos (alfa $>0,60$ ) e diferenciação (alfa > 0,70), segundo Hair Jr. et al. (2009), tanto para as firmas dos países do BRICS como do G7, podem ser considerados aceitáveis. Além disso, devido a cada fator possuir apenas três variáveis, optou-se por avaliar a confiabilidade composta por cada constructo, conforme sugerido por Hair Jr. et al. (2009). A partir do coeficiente de confiabilidade de Fornell e Larcker (1981), pode-se dizer que os constructos apresentam consistência interna, com índices superiores a 0,70, sugerindo que as medidas representam adequadamente o mesmo constructo latente (Fornell \& Larcker, 1981; Hair Jr. et al., 2009), conforme Tabelas 1 e 2.

A adequação da análise fatorial foi analisada a partir dos testes de Kaiser-Meyer-Olkin (KMO) e de Bartlett. Os resultados dos testes, conforme Tabelas 2 e 3, apontaram que a análise fatorial é adequada e pode ser utilizada (KMO $=0,521$ e $\mathrm{KMO}=0,576$, respectivamente), indicando que a correlação entre as variáveis examinadas é estatisticamente significante (teste de Bartlett $=1.513,455, p<0,01$; e teste de Bartlett $=4.391,544, p<0,01$, respectivamente) .

Tabela 3:

Análise fatorial exploratória e confirmatória dos constructos: empresas de países membros do G7

\begin{tabular}{|c|c|c|c|c|}
\hline 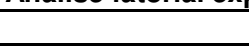 & Painel A - Análise fa & ial exploratória (201 & 7) & \\
\hline Variáveis & $\begin{array}{l}\text { Liderança em custos } \\
\text { (cargas fatoriais) }\end{array}$ & $\begin{array}{l}\text { Diferenciação } \\
\text { (cargas fatoriais) }\end{array}$ & Comunalidades & \\
\hline DVGA/RL & 0,37 & 0,76 & 0,72 & \\
\hline $\mathrm{P} \& \mathrm{D} / \mathrm{RL}$ & 0,54 & 0,61 & 0,66 & \\
\hline $\mathrm{VA} / \mathrm{RL}$ & 0,53 & 0,67 & 0,73 & \\
\hline CAPEX/RL & 0,67 & $-0,63$ & 0,84 & \\
\hline AIL/RL & 0,62 & $-0,71$ & 0,85 & \\
\hline AT/NE & 0,59 & $-0,20$ & 0,39 & \\
\hline Variância explicada & 1,88 & 2,32 & & \\
\hline Alfa de Cronbach & 0,76 & 0,67 & & \\
\hline KMO & & & & 0,576 \\
\hline Teste de Bartlett & & & & $4.391,544^{\star \star \star}$ \\
\hline & Painel B - Análise fa & al confirmatória (201 & & \\
\hline Variáveis & $\begin{array}{l}\text { Liderança em custos } \\
\text { (cargas fatoriais) }\end{array}$ & $\begin{array}{l}\text { Diferenciação } \\
\text { (cargas fatoriais) }\end{array}$ & $\begin{array}{c}\text { Coeficiente de } \\
\text { confiabilidade Fornell e } \\
\text { Larcker (1981) }\end{array}$ & $\begin{array}{l}\text { Variância } \\
\text { média } \\
\text { extraída } \\
\text { (VME) }\end{array}$ \\
\hline DVGA/RL & & 0,81 & 0,87 & 0,69 \\
\hline$P \& D / R L$ & & 0,65 & & \\
\hline $\mathrm{VA} / \mathrm{RL}$ & & 0,77 & & \\
\hline CAPEX/RL & 0,85 & & 0,85 & 0,69 \\
\hline AIL/RL & 1,01 & & & \\
\hline AT/NE & 0,32 & & & \\
\hline Estatísticas de aju & & & & \\
\hline Chi2 & & & $284,612^{\star \star \star}$ & \\
\hline Root mean square & & & 0,034 & \\
\hline Goodness of fit inde & & & 0,950 & \\
\hline Goodness of fit inde & ees of freedom (AGFI) & & 0,882 & \\
\hline Normed fit index ( $N$ & & & 0,917 & \\
\hline Comparative fit inde & & & 0,920 & \\
\hline
\end{tabular}

Notas: Significância estatística: ${ }^{\star \star *} \mathrm{p}<0,01$. Todas as variáveis foram padronizadas. DVGA/RL é a relação entre as despesas gerais, de vendas e administrativas com a receita líquida; $P \& D / R L$ é a relação entre os gastos com $P \& D$ e a receita líquida; VA/RL é a relação entre o valor adicionado bruto e a receita líquida; CAPEX/RL é a relação entre as despesas de capital e a receita líquida; $A I L / R L$ é a relação entre o ativo imobilizado líquido e a receita líquida; AT/NE é a relação entre o ativo total e o número de empregados.

Fonte: elaboração própria.

Posteriormente, foi realizada a análise fatorial confirmatória para validar as medidas de estratégia competitiva. Os resultados estão apresentados no Painel B das Tabelas 2 e 3 . As estatísticas de ajuste do modelo indicam que os modelos se mostraram ajustados. O teste de ajuste geral do modelo (GFI) foi de 0,943 e 0,950 , indicando um bom ajuste geral dos modelos. As demais estatísticas de ajustes do modelo também apontaram para a sua adequação.

Com relação à validade convergente da análise fatorial confirmatória, observando-se o resultado da variância média extraída (VME), conforme Painel B das Tabelas 2 e 3, pode-se afirmar que a variância comum compartilhada entre as variáveis dos dois constructos é convergente e confiável. Já o coeficiente de confiabilidade conjunta de Fornell e Larcker (1981) aponta que o modelo apresenta validade convergente, isto é, confiabilidade. Por fim, com base nos resultados da análise fatorial confirmatória, sugere-se que os constructos das estratégias são confiáveis e aceitáveis para a amostra das empresas dos países membros do BRICS (China e Índia) e do G7. 


\subsection{Análises das estimações de empresas de países membros do BRICS}

Inicialmente, destaca-se que apenas foram considerados para análise os modelos e as variáveis que apresentaram significância estatística ao nível de $1 \%$ e $5 \%$. Todos os modelos exibidos na Tabela 4 foram estimados pelo GMM-sistema utilizando-se o procedimento two-step, com erros padrões robustos para corrigir o problema de heterocedasticidade, bem como que o painel se encontra balanceado. Destacase que os modelos foram estimados com o número de instrumentos inferior ao número de grupos, uma vez que o número de instrumentos não pode ser superior ao número de grupos, conforme sugerido pela literatura (Labra \& Torrecillas, 2018; Roodman, 2009).

De acordo com os resultados do teste de Wald, pode-se dizer que as estimações expostas na Tabela 4 apresentam significância estatística $(p<0,01)$. Com relação aos pressupostos do modelo de painel dinâmico, o teste para autocorrelação de segundo grau (AR2) indica a ausência de autocorrelação para todas as estimações (modelos 1, 2, 3, 4 e 5), demonstrando que os estimadores dos modelos são consistentes. Além disso, mediante a estatística variance inflation fator (VIF), observou-se que as variáveis presentes nos modelos não apresentaram problema de multicolinearidade.

Os resultados expostos na Tabela 4 sugerem que o desempenho anterior $\left(R O A_{i t-1}\right)$ foi persistente durante o período analisado, variando de 0,606 a 0,670, mostrando-se estatisticamente significante, ao nível de $1 \%$, para as todas as estimações. Com relação às estratégias competitivas, considerando-se o modelo 1 , observa-se que apenas a estratégia de liderança em custos $\left(L C_{i t}\right)$ apresentou uma relação positiva e estatisticamente significante, ao nível de $1 \%$, com o desempenho financeiro $\left(R O A_{i t}\right)$, indicando que essa estratégia contribuiu para o desempenho das empresas. Este resultado está consistente com a literatura (Banker et al., 2014; Cho \& Lee, 2018; Hambrick, 1983; Junqueira et al., 2016; Porter, 1980), que prevê que uma estratégia baseada na liderança em custos possibilita às companhias alcançarem desempenho superior ao de seus concorrentes.

Já para a estratégia baseada na diferenciação (modelo 1), as evidências apontam uma relação negativa com o desempenho financeiro, mas sem significância estatística. Tal resultado pode ser explicado pelas características dos ambientes onde as empresas operam. A Índia e a China passaram por um processo de transição na economia, permitindo maior liberação econômica (Fedato et al., 2017; Gopalakrishna \& Subramanian, 2001; Parnell et al., 2015). Além disso, segundo Parnell et al. (2015), no contexto chinês, por exemplo, as empresas tendem a utilizar uma estratégia baseada na liderança em custos ou no foco, devido à baixa incerteza do ambiente.

Tabela 4:

Resultados da estimação do modelo para empresas de países membros do BRICS (2012-2018)

\begin{tabular}{|c|c|c|c|c|c|c|}
\hline Variáveis & & $\begin{array}{l}\text { Modelo } 1 \\
\text { Coeficiente }\end{array}$ & $\begin{array}{l}\text { Modelo } 2 \\
\text { Coeficiente }\end{array}$ & $\begin{array}{l}\text { Modelo } 3 \\
\text { Coeficiente }\end{array}$ & $\begin{array}{l}\text { Modelo } 4 \\
\text { Coeficiente }\end{array}$ & $\begin{array}{l}\text { Modelo } 5 \\
\text { Coeficiente }\end{array}$ \\
\hline$R O A_{i t-1}$ & + & $0,653^{* *}$ & $0,620^{* *}$ & $0,670^{\star *}$ & $0,650^{\star *}$ & $0,606^{* *}$ \\
\hline$L C_{i t}$ & + & $0,015^{\star *}$ & $0,015^{\star *}$ & 0,001 & $0,013^{\star *}$ & 0,004 \\
\hline$D I F_{i t}$ & + & $-0,004$ & $-0,004$ & $-0,006$ & $-0,001$ & $-0,009$ \\
\hline$N C_{j t}$ & - & 0,050 & $-0,019$ & 0,036 & 0,031 & 0,058 \\
\hline$I N C_{i t}$ & - & $0,229^{* *}$ & $0,202^{* *}$ & $0,197^{* *}$ & $0,147^{* *}$ & $0,194^{* *}$ \\
\hline$P E Q_{i t}$ & + & 0,010 & 0,010 & $-0,008$ & 0,002 & 0,009 \\
\hline$G P_{i t}$ & + & $-0,021$ & $-0,008$ & $-0,004$ & $-0,012$ & $-0,013$ \\
\hline$I D_{i t}$ & + & $-0,001^{*}$ & $-0,001^{*}$ & $-0,001$ & $-0,001^{*}$ & $-0,001^{*}$ \\
\hline$E N D_{i t}$ & - & $-0,023$ & $-0,048$ & $-0,064$ & $-0,037$ & $-0,037$ \\
\hline$C E_{j t}$ & & $-0,209$ & $-0,361$ & $-0,021$ & $-0,280$ & $-0,319$ \\
\hline$N C_{i t} \times D I F_{i t}$ & & & 0,036 & & & \\
\hline$N C_{i t} \times L C_{i t}$ & & & 0,008 & & & \\
\hline$I N C_{i t} \times D I F_{i t}$ & & & & 0,011 & & \\
\hline$I N C_{i t} \times L C_{i t}$ & & & & $0,048^{*}$ & & \\
\hline$P E Q_{i t} \times D I F_{i t}$ & & & & & 0,002 & \\
\hline$P E Q_{i t} \times L C_{i t}$ & & & & & $-0,007$ & \\
\hline$G P_{i t} \times D I F_{i t}$ & & & & & 0,002 & \\
\hline$G P_{i t} \times L C_{i t}$ & & & & & $-0,008$ & \\
\hline$I D_{i t} \times D I F_{i t}$ & & & & & & $0,0002^{\star *}$ \\
\hline$I D_{i t} \times L C_{i t}$ & & & & & & $0,0004^{\star *}$ \\
\hline DInd & & Sim & Sim & Sim & Sim & Sim \\
\hline DPaís & & Sim & Sim & Sim & Sim & Sim \\
\hline Constante & & $0,100^{*}$ & $0,121^{*}$ & 0,097 & $0,090^{*}$ & $0,085^{*}$ \\
\hline Observações & & 1.434 & 1.434 & 1.434 & 1.434 & 1.434 \\
\hline Instrumentos & & 103 & 123 & 123 & 143 & 123 \\
\hline Grupos & & 205 & 205 & 205 & 205 & 205 \\
\hline Teste de Wald & & $240,44^{\star *}$ & $316,91^{* *}$ & $330,74^{\star *}$ & $358,74^{* *}$ & $269,81^{* *}$ \\
\hline AR1 (p-valor) & & $0,000^{* *}$ & $0,000^{* *}$ & $0,000^{* *}$ & $0,000^{* *}$ & $0,000^{* *}$ \\
\hline AR2 (p-valor) & & 0,328 & 0,364 & 0,292 & 0,344 & 0,275 \\
\hline $\begin{array}{l}\text { Teste de Hansen } \\
\text { (p-valor) }\end{array}$ & & 0,321 & 0,264 & 0,293 & 0,659 & 0,373 \\
\hline
\end{tabular}

(p-valor)

Nota: Significância: * $p<0,05 e^{* *} p<0,01$.

Fonte: elaboração própria. 
No que se refere às demais variáveis explicativas, os resultados do modelo 1 sugerem que a incerteza afeta positivamente o desempenho das empresas, sendo significativa ao nível $1 \%$. Conforme mencionado anteriormente, tal evidência pode ser explicada devido ao baixo nível de competitividade e de incerteza presente no mercado chinês e indiano, conforme citado na literatura (Gopalakrishna \& Subramanian, 2001; Parnell et al., 2015).

De acordo com o modelo 1, não se encontraram as relações esperadas entre o nível de competição e as variáveis relativas ao tamanho organizacional com o desempenho financeiro. Ainda com base no modelo 1, verificou-se uma associação negativa e significativa ao nível de $5 \%$ entre a idade da organização e o desempenho financeiro, podendo sugerir que, no período em análise, a evolução das empresas ao longo do tempo não contribui para aumentar o retorno dos ativos.

Do modelo 2 ao 5, observam-se as interações entre as estratégias competitivas $\left(L C_{i t}\right.$ e $\left.D I F_{i t}\right)$ e os fatores contingenciais externos $\left(N C_{j t}\right.$, e $\left.I N C_{i t}\right)$ e internos $\left(P E Q_{i t}, G P_{i t}\right.$ e $\left.I D_{i t}\right)$. Com base nos resultados apresentados no modelo 3, conforme Tabela 4, observou-se que o coeficiente de interação entre o nível de incerteza e a estratégia de liderança em custos mostrou-se positivo e estatisticamente significante, ao nível de $5 \%$. Tal resultado pode sugerir que uma estratégia de liderança em custos auxilia as empresas a enfrentarem a incerteza do ambiente, gerando resultados financeiros positivos, conforme previsto pela literatura (Allen \& Helmms, 2006; Hambrick, 1983; Huo et al., 2014; Porter, 1980).

Além disso, essa evidência do papel moderador da estratégia de liderança em custos em relação ao nível de incerteza pode ser explicada devido às características do ambiente chinês e indiano, onde o baixo nível de incerteza possibilita a padronização e formalização de tarefas e rotinas organizacionais, permitindo que a estratégia de liderança em custos seja efetiva, conforme sugerido por Huo et al. (2014) e Parnel et al. (2015).

Já com base no modelo 5, encontraram-se relações positivas e significativas ao nível de $1 \%$ nas interações entre a idade da organização e as estratégias competitivas. Essas evidências sugerem que tanto a estratégia de liderança em custos como a estratégia de diferenciação podem moderar os efeitos do tempo sobre o desempenho das empresas. Esse resultado também pode demonstrar que, com o passar dos anos, as empresas que utilizam uma estratégia baseada na liderança em custos buscam empregar o conhecimento adquirido ao longo do tempo para otimizar suas atividades, tornando-se eficientes e melhorando o desempenho organizacional. Já para as firmas que buscam empregar uma estratégia de diferenciação, tal evidência pode indicar que, ao longo do tempo, por exemplo, essas companhias buscaram empregar mais recursos para melhorar os produtos, tornando-os diferenciados e mais conhecidos no mercado (reputação).

Com base nos resultados estimados para as empresas localizadas na China e na Índia, pode-se dizer que há indícios de que as estratégias competitivas podem atuar para reduzir os efeitos dos fatores contingenciais sobre o desempenho financeiro das companhias. Além disso, os resultados reportados estão em consonância com os achados de Chen et al. (2018) e Huo et al. (2014), apontando que as estratégias competitivas podem moderar os efeitos de fatores contingenciais sobre o desempenho financeiro.

\subsection{Análises das estimações de empresas de países membros do G7}

Apresentam-se na Tabela 5 os resultados das estimações do modelo de painel dinâmico para as companhias sediadas em países membros do G7 (Alemanha, Canadá, EUA, Japão e Reino Unido). Estimaram-se todos os modelos com base no método GMM-sistema, pelo método two-step, com erros padrões robustos para correção da heterocedasticidade e o painel encontra-se balanceado. Apenas foram consideradas para análise os modelos e as variáveis que apresentaram significância estatística ao nível de $1 \%$ e $5 \%$.

Os resultados apresentados na Tabela 5 indicam que todos os modelos $(6,7,8,9$ e 10) foram estimados com o número de instrumentos inferior ao número de grupos, conforme sugerido pela literatura (Roodman, 2009), bem como que, pelo teste de Wald, todos os modelos apresentam significância estatística. Além disso, o teste para autocorrelação de segundo grau (AR2) e o teste de Hansen indicam a consistência dos estimadores e a validade dos instrumentos, respectivamente, para todos os modelos. Ressalta-se, ainda, que, com base na estatística VIF, observou-se a ausência de multicolinearidade entre as variáveis presentes nos modelos.

De acordo com o exposto na Tabela 5, verificou-se uma relação positiva entre o desempenho anterior e o desempenho atual das empresas, sendo tal relação estatisticamente significante ao nível de $1 \%$ para todos os modelos, indicando que as companhias apresentaram resultados persistentes ao longo do período analisado.

No que se refere às relações entre as estratégias competitivas e o desempenho financeiro, conforme modelo 6 , os resultados apontam que as estratégias de liderança em custos e diferenciação não contribuíram para a performance das companhias, no período analisado. Ainda de acordo com o modelo 6 , não se observaram as associações esperadas entre as variáveis $N C_{i t}, I N C_{i t}, P E Q_{i t}, G P_{i t}$ e $I D_{i t}$ com 0 desempenho das empresas. 
Tabela 5:

Resultados da estimação do modelo para empresas de países membros do G7 (2012-2018)

\begin{tabular}{|c|c|c|c|c|c|c|}
\hline Variáveis & & $\begin{array}{l}\text { Modelo } 6 \\
\text { Coeficiente }\end{array}$ & $\begin{array}{l}\text { Modelo } 7 \\
\text { Coeficiente }\end{array}$ & $\begin{array}{l}\text { Modelo } 8 \\
\text { Coeficiente }\end{array}$ & $\begin{array}{l}\text { Modelo } 9 \\
\text { Coeficiente }\end{array}$ & $\begin{array}{l}\text { Modelo } 10 \\
\text { Coeficiente }\end{array}$ \\
\hline$R O A_{i t-1}$ & + & $0,670^{* \star}$ & $0,627^{\star *}$ & $0,678^{\star *}$ & $0,680^{\star *}$ & $0,671^{\star *}$ \\
\hline$L C_{i t}$ & + & 0,0001 & $-0,005$ & $-0,004$ & $-0,001$ & $0,029^{*}$ \\
\hline$D I F_{i t}$ & + & $-0,065$ & $-0,014$ & $-0,007$ & $-0,013$ & $-0,021^{*}$ \\
\hline$N C_{j t}$ & - & 0,036 & 0,081 & $-0,006$ & $-0,107$ & 0,097 \\
\hline$I N C_{i t}$ & - & 0,128 & 0,365 & 0,111 & 0,150 & 0,047 \\
\hline$P E Q_{i t}$ & + & $-0,009$ & $-0,093$ & $-0,0002$ & 0,007 & $-0,027$ \\
\hline$G P_{i t}$ & + & 0,021 & $-0,029$ & 0,013 & 0,026 & $-0,014$ \\
\hline$I D_{i t}$ & + & 0,0001 & $-0,0001$ & 0,0001 & 0,0001 & 0,0001 \\
\hline$E N D_{i t}$ & - & $-0,023$ & $-0,141$ & $-0,004$ & $-0,019$ & 0,019 \\
\hline$C E_{j t}$ & & $0,325^{\star \star}$ & 0,134 & $0,333^{* *}$ & $0,308^{\star *}$ & $0,227^{*}$ \\
\hline$N C_{i t} \times D I F_{i t}$ & & & 0,031 & & & \\
\hline$N C_{i t} \times L C_{i t}$ & & & 0,045 & & & \\
\hline$I N C_{i t} \times D I F_{i t}$ & & & & 0,011 & & \\
\hline$I N C_{i t} \times L C_{i t}$ & & & & $0,087^{* *}$ & & \\
\hline$P E Q_{i t} \times D I F_{i t}$ & & & & & $-0,013$ & \\
\hline$P E Q_{i t} \times L C_{i t}$ & & & & & 0,022 & \\
\hline$G P_{i t} \times D I F_{i t}$ & & & & & $0,042^{*}$ & \\
\hline$G P_{i t} \times L C_{i t}$ & & & & & 0,006 & \\
\hline$I D_{i t} \times D I F_{i t}$ & & & & & & $-0,0003$ \\
\hline$I D_{i t} \times L C_{i t}$ & & & & & & 0,0002 \\
\hline DInd & & Sim & Sim & Sim & Sim & Sim \\
\hline DPaís & & Sim & Sim & Sim & Sim & Sim \\
\hline Constante & & $0,100^{*}$ & $0,121^{*}$ & 0,097 & $0,090^{*}$ & $0,085^{*}$ \\
\hline Observações & & 3.989 & 3.989 & 3.989 & 3.989 & 3.989 \\
\hline Instrumentos & & 96 & 88 & 112 & 128 & 136 \\
\hline Grupos & & 570 & 570 & 570 & 570 & 570 \\
\hline Teste de Wald & & $309,38^{\star *}$ & $238,14^{\star *}$ & $359,69^{\star *}$ & $323,35^{\star *}$ & $420,23^{* *}$ \\
\hline AR1 (p-valor) & & $0,000^{* *}$ & $0,000^{* *}$ & $0,000^{* *}$ & $0,000^{\star *}$ & $0,000^{* *}$ \\
\hline AR2 (p-valor) & & 0,058 & 0,082 & 0,074 & 0,070 & 0,065 \\
\hline $\begin{array}{l}\text { Teste de Hansen } \\
\text { (p-valor) }\end{array}$ & & 0,100 & 0,382 & 0,171 & 0,178 & 0,131 \\
\hline
\end{tabular}

Nota: Significância: * $p<0,05 e^{* *} p<0,01$.

Fonte: elaboração própria.

A partir do modelo 7 até o modelo 10 , conforme Tabela 5 , pôde-se verificar os resultados para as interações entre os fatores contingenciais $\left(N C_{i t}, I N C_{i t}, P E Q_{i t}, G P_{i t}\right.$ e $\left.I D_{i t}\right)$ e as estratégias competitivas $\left(L C_{i t}\right.$ e $\left.D I F_{i t}\right)$. De acordo com o modelo 8, encontrou-se uma relação positiva e significativa, ao nível de $1 \%$, entre a estratégia de liderança em custos e o nível de incerteza, sugerindo que essa estratégia pode reduzir os efeitos da incerteza sobre o desempenho das firmas, contribuindo para o aumento do desempenho financeiro. Este resultado pode indicar que a estratégia competitiva pode moderar os efeitos dos fatores contingenciais sobre o desempenho corporativo.

Tal evidência pode indicar que, para enfrentar a incerteza do ambiente, as organizações que utilizam uma estratégia baseada na liderança em custos buscam, por exemplo, realizar investimentos para otimizar a estrutura organizacional, aumentando a eficiência da capacidade de produção e na utilização de recursos (Banker et al., 2014; Hambrick, 1983; Huo et al., 2014; Porter, 1980), buscando manter sua estrutura ajustada e sustentar o desempenho em longo prazo.

No que se refere às interações entre as variáveis que representam o tamanho organizacional $\left(P E Q_{i t}\right.$ e $\left.G P_{i t}\right)$ e as estratégias competitivas $\left(L C_{i t}\right.$ e $D I F_{i t}$ ), conforme modelo 9, os resultados apontam um coeficiente de interação positivo e significativo, ao nível de $5 \%$, entre a variável $G P_{i t}$ e a estratégia de diferenciação, sugerindo que essa estratégia pode reduzir os efeitos do porte corporativo sobre 0 desempenho financeiro das companhias.

Esse resultado pode indicar que empresas de grande porte, que utilizam uma estratégia de diferenciação por possuírem mais recursos e maior controle do ambiente operacional (Chenhall, 2003), conseguem investir mais em P\&D, por exemplo, tornando seus produtos conhecidos pelos atributos e qualidades distintas, mantendo-se sempre à frente de seus competidores, em termos de inovação e desempenho diferenciados dos outros (Banker et al., 2014; Cho \& Lee, 2018; Hambrick, 1983; Huo et al., 2014; Junqueira et al., 2016; Porter, 1980).

As evidências reportadas reforçam as evidenciadas nos estudos de Chen et al. (2018), HernándezPerlines et al. (2016), Mohsenzadeh e Ahmadian (2016) e Santos (2015), apontando que as estratégias competitivas podem moderar os efeitos dos fatores contingenciais externos e internos sobre o desempenho financeiro.

Portanto, a partir dos resultados expostos, aponta-se que, para o ambiente das empresas localizadas em países membros do G7, no período analisado, parece que a estratégia de liderança em custos contribuiu para reduzir os efeitos da incerteza e que a estratégia baseada na diferenciação modera a influência do porte corporativo sobre o desempenho das empresas, gerando resultados financeiros positivos. 


\section{Considerações Finais}

O ambiente organizacional é caracterizado por diversos fatores contingenciais que moldam a estrutura corporativa. Dentre esses fatores, a estratégia competitiva é vista como uma variável mediadora que pode ser utilizada pelas entidades para adequar suas atividades e reduzir as influências dos demais fatores contingenciais sobre o desempenho financeiro.

Neste sentido, a presente pesquisa teve por objetivo analisar a relação da estratégia competitiva (liderança em custos ou diferenciação) com os fatores contingenciais (incerteza do ambiente, nível de competição, tamanho e idade da organização) sobre o desempenho financeiro de empresas, considerandose o ambiente em que estão localizadas (países membros do BRICS e do G7).

As evidências encontradas indicaram que, no ambiente dos países do BRICS, a estratégia de liderança em custos afeta positivamente o desempenho financeiro das empresas. Esse resultado indica que a estratégia de liderança em custos parece aumentar o desempenho financeiro das organizações.

De acordo com os resultados da análise de dados em painel, não foram encontradas as relações esperadas entre os fatores contingenciais e o desempenho financeiro. Por outro lado, as evidências apontam que, para as empresas sediadas em países membros do BRICS (China e Índia), a estratégia de liderança em custos parece reduzir os efeitos da incerteza e da idade da organização sobre os resultados financeiros das empresas. Além disso, verificou-se que a estratégia de diferenciação pode moderar a influência da idade da organização sobre o desempenho financeiro.

Com relação aos países membros do G7 (Alemanha, Canada, EUA, Japão e Reino Unido), os resultados sugerem que, no período analisado, a estratégia de liderança em custos modera os efeitos da incerteza sobre o retorno dos ativos, e que a estratégia de diferenciação parece atenuar a influência do porte corporativo sobre o desempenho financeiro.

A partir das evidências encontradas, pode-se dizer que há indícios de que, no ambiente dos países do BRICS, a estratégia de liderança em custos parece reduzir os efeitos da incerteza e da idade da organização e a estratégia de diferenciação modera a influência da idade da organização sobre o desempenho financeiro das companhias, bem como que, nos países membros do G7, a estratégia de liderança em custos parece moderar os efeitos da incerteza e a estratégia de diferenciação do tamanho sobre o desempenho financeiro, no período analisado.

Esses resultados também demonstram a aplicabilidade da teoria da contingência, confirmando a premissa de que as organizações devem se adequar ao contexto em que atuam, uma vez que o ambiente (interno e externo) molda as estruturas corporativas, bem como que a estratégia competitiva pode ser utilizada como um meio para moderar as influências dos fatores contingenciais sobre o desempenho das organizações.

Como implicações práticas e empíricas, os resultados sugerem que os gestores, controllers e demais envolvidos na gestão organizacional devem buscar escolher a estratégia competitiva que se adeque ao ambiente organizacional e que possa moderar as influências dos fatores contingenciais, buscando otimizar o desempenho financeiro das companhias, tornando-o sustentável ao longo do tempo. Além disso, precisam entender os fatores contingenciais e a dinâmica do ambiente em que a organização está inserida para empregar a estratégia competitiva mais adequada a cada contexto.

Salienta-se que os resultados apresentados devem ser considerados com diligência e que se restringem à amostra de empresas investigadas no período abordado. Ademais, não se pode afirmar, de forma categórica, que uma determinada estratégia competitiva específica é mais eficiente em moderar as influências dos fatores contingenciais sobre o desempenho financeiro das empresas, conforme o ambiente em que atuam (países desenvolvidos ou em desenvolvimento), sendo que outras variáveis, não contempladas por esta pesquisa, podem atuar na escolha da estratégia competitiva a ser utilizada por uma organização. Desta forma, devem-se analisar as evidências apresentadas no contexto do presente estudo, sendo as evidências válidas apenas para as entidades analisadas e para o período avaliado.

Algumas limitações potenciais desta pesquisa devem ser levadas em consideração quando da interpretação dos resultados, tais como: o número de períodos analisados; o reduzido número de empresas estudadas de países em desenvolvimento; as diferenças no período de encerramento demonstrações contábeis; e a não inclusão de outros fatores contingenciais, como variáveis psicológicas, mudanças nos sistemas de controle, cultura nacional, entre outras que podem afetar o desempenho das companhias.

Considerando-se as limitações mencionadas, e por ser um tema que carece de mais estudos, pretende-se, em pesquisas futuras, aumentar o número de períodos analisados, incluir novos fatores contingenciais, aumentar o número de países a serem analisados, utilizar outras variáveis para poder captar a estratégia competitiva baseada no foco e aplicar outras teorias e métodos econométricos, buscando evidenciar o papel da estratégia competitiva na redução das influências dos fatores contingenciais sobre o desempenho organizacional.

\section{REFERÊNCIAS}

Acquaah, M., \& Agyapong, A. (2016). Dynamic tensions from Management Control Systems and 
performance in a Sub-Saharan African Economy: mediating effects of competitive strategy. Africa Journal of Management, 2(4), 395-421. https://doi.org/10.1080/23322373.2016.1256178

Allen, R. S., \& Helms, M. M. (2006). Linking strategic practices and organizational performance to Porter's generic strategies. Business Process Management Journal, 12(4), 433-454.

https://doi.org/10.1108/14637150610678069

Andrade, L. C. M., Teixeira, A. J. C., Fortunato, G., \& Nossa, V. (2013). Determinantes para utilização de práticas de contabilidade gerencial estratégica: um estudo empírico. Revista de Administração Mackenzie, 14(1), 98-125. https://doi.org/10.1590/S1678-69712013000100005

Anwar, J., \& Hasnu, S. A. F. (2017). Strategy-performance relationships: A comparative analysis of pure, hybrid, and reactor strategies. Journal of Advances in Management Research, 14(4), 446-465.

https://doi.org/10.1108/JAMR-07-2016-0056

Asdemir, O., Fernando, G. D., Schneible Jr., R. A., \& Tripathy, A. (2017). Impact of strategy on analyst information. Advances in Accounting, 37(2), 103-110. https://doi.org/10.1016/..adiac.2016.12.003

Balsam, S., Fernando, G. D., \& Tripathy, A. (2011). The impact of firm strategy on performance measures used in executive compensation. Journal of Business Research, 64(2), 187-193. https://doi.org/10.1016/i.jbusres.2010.01.006

Baltagi, B. H. (2005). Econometric analysis of panel data. Editora John Wiley \& Sons Ltd.

Banker, R., Mashruwala, R., \& Tripathy, A. (2014). Does a differentiation strategy lead to more sustainable financial performance than a cost leadership strategy? Management Decision, 52(5), 872-896. https://doi.org/10.1108/MD-05-2013-0282

Boyd, B. K., \& Salamin, A. (2001). Strategic reward systems: a contingency model of pay system design. Strategic Management Journal, 22(8), 777-792. https://doi.org/10.1002/smi.170

Capalonga, G., Diehl, C. A., \& Zanini, F. A. M. (2014). Estratégias percebidas sob o foco da teoria de posicionamento estratégico, da visão baseada em recursos, da missão estratégica e da tipologia organizacional: um estudo com empresas do sul do Brasil. Brazilian Business Review, 11(3), 29-55. https://doi.org/10.15728/bbr.2014.11.3.2

Chandler Jr., A. P. (1962). Strategy and structure: chapters in the history of the American enterprise. The MIT Press.

Chaves, S., Benedete, T., \& Polo, E. (2009). Estratégias genéricas: um estudo evolutivo e comparativo de três visões. Internext - Revista Eletrônica de Negócios Internacionais da ESPM, 4(2), 101118. http://dx.doi.org/10.18568/1980-4865.42101-118

Chen, C., Guo, R., Hsiao, Y., \& Chen, K. (2018). How business strategy in non-financial firms moderates the curvilinear effects of corporate social responsibility and irresponsibility on corporate financial performance. Journal of Business Research, 92(11), 154-167. https://doi.org/10.1016/j.jbusres.2018.07.030

Cheng, J. L. C., \& Kesner, I. F. (1997). Organizational slack and response to environmental shifts: the impact of resource allocation patterns. Journal of Management, 23(1), 68-86. https://doi.org/10.1016/S01492063(97)90003-9

Chenhall, R. H. (2003). Management control systems design within its organizational context: findings from contingency-based research and directions for the future. Accounting, Organizations and Society, 28(2-3), 127-168. https://doi.org/10.1016/S0361-3682(01)00027-7

Cho, J., \& Lee, J. (2018). Internationalization and performance of Korean SMEs: the moderating role of competitive strategy. Asian Business \& Management, 17(2), 140-166. https://doi.org/10.1057/s41291-018$\underline{0036-8}$

Donaldson, L. (1999). Teoria da contingência estrutural. In S. R. Clegg, C. Hardy, \& W. R. Nord (Orgs.). Handbook de Estudos Organizacionais: modelos de análise e novas questões em estudos organizacionais (vol. 1, pp. 105-127). Editora Atlas. 
Donaldson, L. (2015). Structural contingency theory. International Encyclopedia of the Social \& Behavioral Sciences (Second Edition), 23, 609-614. https://doi.org/10.1016/B978-0-08-097086-8.73110-2

Ewsi-Mensah, K. (1981). The external organizational environment and its impact on management information systems. Accounting, Organization and Society, 6(4), 301-316. https://doi.org/10.1016/0361$\underline{3682(81) 90010-6}$

Fedato, G. A. L., Pires, V. M., \& Trez, G. (2017). O futuro da pesquisa em implementação de estratégia no contexto do BRICS. Brazilian Business Review, 14(3), 288-303. https://doi.org/10.15728/bbr.2017.14.3.2

Field, A. (2009). Descobrindo estatística usando o SPSS. Editora Armed.

Fornell, C., \& Larcker, D. (1981). Evaluating structural equation models with unobservable variables and measurement errors. Journal of Marketing Research, 18(1), 39-50.

https://doi.org/10.1177/002224378101800104

Gopalakrishna, P., \& Subramanian, R. (2001). Revisiting the pure versus hybrid dilemma, Journal of Global Marketing, 15(2), 61-79. https://doi.org/10.1300/J042v15n02 04

Govindarajan, V. (1984). Appropriateness of accounting data in performance evaluation: an empirical examination of environmental uncertainty as an intervening variable. Accounting, Organizations and Society, 9(2), 125-136. https://doi.org/10.1016/0361-3682(84)90002-3

Greiner, L. E. (1972). Evolution and revolution as organizations grow. Harvard Business Review, 50(4), 3746.

Gupta, A. K., \& Govindarajan, V. (1984). Business unit strategy, managerial characteristics, and business unit effectiveness at strategy implementation. The Academy of Management Journal, 27(1), 25-41.

https://doi.org/10.2307/255955

Hair Jr., J. F., Black, W. C., Babin, B. J., Anderson, R. E., \& Tatham, R. L. (2009). Análise multivariada de dados. Bookman editora.

Hair, J. F., Ringle, C. M., \& Sarstedt, M. (2011). PLS-SEM: Indeed a Silver Bullet. Journal of Marketing Theory and Practice, 19(2), 139-152. https://doi.org/10.2753/MTP1069-6679190202

Hamann, P. M. (2017). Towards as contingency theory of corporate planning: a systematic literature review. Management Review Quarterly, 67(4), 227-289. https://doi.org/10.1007/s11301-017-0132-4

Hambrick, D. C. (1983). Some tests of the effectiveness and functional attributes of Miles and Snow's strategic types. The Academy of Management Journal, 26(1), 5-26. https://doi.org/10.2307/256132

Harrison, G. L. (1993). Reliance on accounting performance measures in superior evaluation style: the influence of national culture and personality. Accounting, Organizations, and Society, 18(4), 319-339. https://doi.org/10.1016/0361-3682(93)90019-3

Herbert, T. T., \& Deresky, H. (1987). Generic strategies: an empirical investigation of typology validity and strategy content. Strategic Management Journal, 8(2), 135-147. https://doi.org/10.1002/smi.4250080205

Hernández-Perlines, F., Moreno-Gárcia, J., \& Yañz-Araque, B. (2016). The mediating role of competitive strategy in international entrepreneurial orientation. Journal of Business Research, 69(11), 5383-5389. https://doi.org/10.1016/j.jbusres.2016.04.142

Hofer, C. W. (1975). Toward a contingency theory of business strategy. The Academy of Management Journal, 18(4), 784-810. https://doi.org/10.2307/255379

Hofstede, G. (1983). The cultural relativity of organizational practices and theories. Journal of International Business Studies, 14(2), 75-89. https://doi.org/10.1057/palgrave.jibs.8490867

Huang, K., Dyerson, R., Wu, L., \& Harindranath, G. (2015). From temporary competitive advantage to sustainable competitive advantage. British Journal of Management, 26(4), 617-636.

https://doi.org/10.1111/1467-8551.12104 
Huo, B., Qi, Y., Wang, Z., \& Zhao, X. (2014). The impact of supply chain integration on firm performance: The moderating role of competitive strategy. Supply Chain Management: An International Journal, 19(4), 369-384. https://doi.org/10.1108/SCM-03-2013-0096

International Monetary Fund. (2019). World Economy Outlook. http://www.imf.org/en/publications/weo.

Jayaram, J., Tan, K. C., \& Laosirihongthong, T. (2014). The contingency role of business strategy on the relationship between operations practices and performance. Benchmarking: An International Journal, 21(5), 690-712. https://doi.org/10.1108/BIJ-10-2012-0066

Junqueira, E. R., Dutra, E. V., Zanquetto Filho, H., \& Gonzaga, R. P. (2016). Efeito de escolhas estratégicas e dos sistemas de controle gerencial no desempenho organizacional. Revista de Contabilidade \& Finanças, 27(72), 334-348. https://doi.org/10.1590/1808-057x201601890

Labra, R., \& Torrecillas, C. (2018). Estimating dynamic panel data: a practical approach to perform long panels. Revista Colombiana de Estadística, 41(1), 31-52. http://dx.doi.org/10.15446/rce.v41n1.61885

Martins, V. Q. (2019). Relação entre os fatores contingenciais e a remuneração variável de executivos. Tese de Doutorado, Universidade do Vale do Rio dos Sinos, Porto Alegre, Brasil.

Mckinley, W., \& Mone, M. A. (2003). Micro and macro perspectives in organization theory: a tale of incommensurability. In H. Tsoukas, \& C. Knudsen (Eds.), The Oxford Handbook of Organizational Theory: meta-theoretical perspectives (pp. 345-372). Oxford University Press.

Miles, R. E., Snow, C. C., Meyer, A. D., \& Coleman Jr., H. J. (1978). Organizational strategy, structure, and process. The Academy of Management Review, 3(3), 546-562. https://doi.org/10.2307/257544

Miller, D. (1992a). Environmental fit versus internal fit. Organization Science, 3(2), 159-178. https://doi.org/10.1287/orsc.3.2.159

Miller, D. (1992b). The generic strategy trap. Journal of Business Strategy, 13(1), 37-41. https://doi.org/10.1108/eb039467

Mintzberg, H. (1978). Patterns in Strategy Formation. Management Science, 24(9), 934-948. https://doi.org/10.1287/mnsc.24.9.934

Mohsenzadeh, M., \& Ahmadian, S. (2016). The mediating role of competitive strategies in the effect of firm competencies and export performance. Procedia Economics and Finance, 36(2), 456-466. https://doi.org/10.1016/S2212-5671(16)30069-7

Otley, D. (2016). The contingency theory of management accounting and control: 1980-2014. Management Accounting Research, 31(2), 45-62. https://doi.org/10.1016/j.mar.2016.02.001

Paredes, A. A. P., \& Wheatley, C. (2017). The influence of culture on real earnings management. International Journal of Emerging Markets, 12(1), 38-57. https://doi.org/10.1108/IJoEM-12-2014-0218

Parnell, J. A., Long, Z., \& Lester, D. L. (2015). Competitive strategy, capabilities and uncertainty in small and medium sized enterprises (SMEs) in China and the United States. Management Decision, 53(2), 402-431. https://doi.org/10.1108/MD-04-2014-0222

Porter, M. E. (1980). Competitive strategy. Free Press.

Porter, M. E. (1985). Competitive advantage: creating and sustaining superior performance. Free Press.

Porter, M. E. (1996). What is strategy? Harvard Business Review, 74(6), 61-78.

https://www.hbs.edu/faculty/Pages/item.aspx?num=10698

Porter, M. E. (2004). Estratégia competitiva: técnicas para análise de indústrias e da concorrência. Elsevier.

Roodman, D. (2009). How to do xtabond2: an introduction to difference and system GMM in

Stata. The Stata Journal, 9(1), 86-136. https://doi.org/10.1177/1536867X0900900106

Rugman, A. M., \& Verbeke, A. (1994). Generic strategies in global competition. In W. Newburry (Ed.), 
Research in Global Strategic Management (pp. 3-15). Emerald Group Publishing Limited. https://doi.org/10.1016/S1064-4857(93)04002-S

Santos, F. R. (2015). As relações entre ambidestria organizacional, capabilidades e seus impactos no desempenho organizacional, moderado pela estratégia. Tese de Doutorado, Universidade Presbiteriana Mackenzie, São Paulo, Brasil.

Shin, E. (2014). Unions and the adoption of high-performance work systems in Korea: moderating roles of firms' competitive strategies. The International Journal of Human Resource Management, 25(13), 18581880. https://doi.org/10.1080/09585192.2013.860386

Snodgrass, C., \& Grant, J. H. (1986). Cultural influences on strategic planning and control systems. Advances in Strategic Management, 4(1), 205-228. https://doi.org/10.1007/978-3-642-49993-7 6

Tenhiälä, A., \& Laamanen, T. (2018). Right on the money? The contingent effects of strategic orientation and pay system design on firm performance. Strategic Management Journal, 39(13), 3408-3433.

https://doi.org/10.1002/smi.2953

Tung, R. L. (1979). Dimensions of organizational environments: an exploratory study of their impact on organization structure. The Academy of Management Journal, 22(4), 672-693.

https://doi.org/10.2307/255808

Xiao, Z. Z., Dyson, J. R., \& Powell, P. L. (1996). The impact of information technology on corporate financial reporting: a contingency perspective. British Accounting Journal, 28(3), 203-227.

https://doi.org/10.1006/bare.1996.0015

\section{NOTAS}

\section{AGRADECIMENTOS}

Não se aplica.

\section{CONTRIBUIÇÃO DE AUTORIA}

Concepção e elaboração do manuscrito: E. T. Bomfim, A. L. C. Callado

Coleta de dados: E. T. Bomfim

Análise de dados: E. T. Bomfim, A. L. C. Callado

Discussão dos resultados: E. T. Bomfim, A. L. C. Callado

Revisão e aprovação: A. L. C. Callado

\section{CONJUNTO DE DADOS DE PESQUISA}

O conjunto de dados que dá suporte aos resultados deste estudo não está disponível publicamente.

\section{FINANCIAMENTO}

Não se aplica.

\section{CONSENTIMENTO DE USO DE IMAGEM}

Não se aplica.

\section{APROVAÇÃO DE COMITÊ DE ÉTICA EM PESQUISA \\ Não se aplica.}

\section{CONFLITO DE INTERESSES}

Não se aplica.

\section{LICENÇA DE USO}

Os Direitos Autorais para artigos publicados neste periódico são do autor, com direitos de primeira publicação para a Revista. Em virtude de aparecerem nesta Revista de acesso público, os artigos são de uso gratuito, com atribuições próprias, em aplicações educacionais, de exercício profissional e para gestão pública. A Revista adotou a licença Creative Commons Atribuição 4.0 Internacional - CC BY NC ND. Esta licença permite acessar, baixar (download), copiar, imprimir, compartilhar, reutilizar e distribuir os artigos desde que com a citação da fonte, atribuindo os devidos créditos de autoria. Nesses casos, nenhuma permissão é necessária por parte dos autores ou dos editores. Autores têm autorização para assumir contratos adicionais separadamente, para distribuição não-exclusiva da versão do trabalho publicada nesta revista (ex.: publicar em repositório institucional ou um capítulo de livro). 


\section{PUBLISHER}

Universidade Federal de Santa Catarina. Curso de Ciências Contábeis e Programa de Pós-graduação em Contabilidade. Publicação no Portal de Periódicos UFSC. As ideias expressadas neste artigo são de responsabilidade de seus autores, não representando, necessariamente, a opinião dos editores ou da universidade.

\section{EDITORES}

Carlos Eduardo Facin Lavarda e Suliani Rover

\section{HISTÓRICO}

Recebido em: 04/08/2020 - Revisado por pares em: 26/11/2020 - Reformulado em: 30/12/2020 Recomendado para publicação em: 07/05/2021 - Publicado em: 30/06/2021 